\title{
Análise do impacto da utilização de um aplicativo móvel para o monitoramento e a qualificação das ações de campo dos Agentes de Combate às Endemias (ACE), no combate ao mosquito Aedes
} aegypti

\section{Impact analysis of the mobile application for monitoring and evaluation of the field actions of the Combat Endemic Agent (ACE), in control of Aedes aegypti}

Leandro Moreira Garcia ${ }^{1}$ Leonardo Ayres Cordeiro ${ }^{2}$

\begin{abstract}
Resumo
O combate ao vetor que transmite a Dengue, o Zica Vírus e a Chikungunya é feito no Brasil por um profissional denominado ACE (Agente de Combate às Endemias); que, além de combater os focos e criadouros, tem a missão de instruir a população quanto aos cuidados necessários para se manter um ambiente não propício à reprodução deste vetor. É um processo feito de forma artesanal, muito dependente da habilidade e comprometimento desses profissionais. O objetivo deste artigo é propor uma alternativa para a informatização do serviço de campo dos ACE, utilizando um aplicativo móvel criado para o monitoramento e a qualificação de suas ações e demonstrar de que forma esta informatização pode trazer benefícios para a gestão municipal, para a produtividade dos profissionais envolvidos, para a população e para a diminuição dos focos e casos das doenças transmitidas pelo vetor. Para a implementação desta solução proposta foram descritas três etapas utilizando a tecnologia como fator viabilizador. Este artigo se baseou em um pré-teste do aplicativo móvel criado, em um município da região metropolitana de Belo Horizonte em Minas Gerais.
\end{abstract}

Palavras chave: Tecnologias móveis. Mosquito Aedes aegypti. Agente de Combate as Endemias (ACE).

\begin{abstract}
The combat against the vector that transmits Dengue, the Zica virus and Chikungunya is made in Brazil by a professional called ACE (Combat Endemic Agent), which, in addition to combat the focus and breeding, has the mission to educate the population as the cares needed to maintain a not conducive environment to the reproduction of this vector. It is a process done in an artisanal way, very dependent on the skill and commitment of these professionals. The aim of this paper is to propose an alternative to computerize the ACE work, using a mobile application designed for monitoring and qualifying their actions, and demonstrate how this computerization can bring benefits to the district administration, to increase the involved workers productivity, to the population and to reduce the focus and cases of diseases transmitted by the vector. For the implementation of this proposed solution, three stages were described using technology as an enabler factor. This article was based on a pretest of the mobile app created, in a district in the metropolitan region of Belo Horizonte in Minas Gerais.
\end{abstract}

Keywords: Mobile Technology. Mosquito Aedes aegypti. Combat Endemic Agent (ACE).

\footnotetext{
Artigo recebido em 08 de junho de 2016 e aprovado em 28 de Junho de 2017.

${ }^{1}$ Especialista em Saúde Pública e Engenheiro de Software. Email: leandro@ planearsistemas.com.br.

${ }^{2}$ Mestre em Administração, pós-graduação em Administração Financeira e em Educação para o Ensino Profissional. Email: leoayres1@gmail.com.
} 


\section{Introdução}

A Gestão Municipal de Saúde, presente em todo município brasileiro, é responsável, dentre outras, pelas ações de combate às endemias. As atividades relacionadas a este setor são executadas, principalmente, pelo ACE (Agente de Combate às Endemias). É um processo feito de forma artesanal, muito dependente da habilidade e comprometimento destes profissionais. A utilização da tecnologia para informatização do serviço de campo dos ACE, utilizando um aplicativo móvel, pode ser uma opção para aumentar a efetividade de seu trabalho, bem como o poder de monitoramento e ação da gestão e, como consequência, diminuir os índices de infestação e incidência das doenças transmitidas pelo mosquito Aedes aegypti.

O processo de trabalho dos ACE segue o modelo tradicional, que é encontrado na maioria dos municípios brasileiros. Os agentes são divididos por regiões e trabalham na maior parte do tempo, fazendo as visitas aos imóveis do município. Durante os períodos do ano em que as doenças transmitidas pelo mosquito Aedes aegypti são mais comuns, estes agentes trabalham exclusivamente com o combate ao vetor. Já no restante do ano, essas atividades são compartilhadas com monitoramento de leishmaniose, infestação de carrapatos, morcegos, caramujos africanos e outros processos de zoonoses.

Nas atividades de combate ao mosquito Aedes aegypti o ACE tem basicamente duas missões: tratar e eliminar os depósitos e focos encontrados e coletar dados para geração do índice de infestação. Durante a atividade de tratamento, o agente precisa visitar os imóveis, eliminar os criadouros, tratar os focos que não podem ser eliminados e instruir o cidadão sobre os cuidados que devem ser tomados. Já as atividades de geração de índice consistem na coleta de amostras de focos para envio ao laboratório municipal para análise.

Existe também um supervisor dos agentes de campo que audita visitas efetuadas pelos mesmos. Aproximadamente $2 \%$ das visitas feitas pelos ACE são auditadas pelo supervisor, que verifica se a visita foi realmente realizada, se os focos e criadouros do mosquito foram eliminados e se o morador foi instruído corretamente quanto aos cuidados necessários.

O mosquito Aedes aegypti é um antigo conhecido dos profissionais da saúde e da população em geral. Desde o início do século XX, este mosquito já era considerado um sério problema, quando a principal questão a ele associada era a transmissão da Febre Amarela.

A infestação do mosquito Aedes aegypti é um problema que vem sendo enfrentado por grande parte dos municípios do Brasil, ainda em 2016. No Portal da Saúde (2016), encontra- 
se o Levantamento do Índice Rápido para o Aedes aegypti (LIRAa) do ano de 2015, cujos dados levantados são dos meses de outubro e novembro de 2015. Segundo estes levantamentos, existem 199 cidades brasileiras em situação de risco de surto de Dengue. Este risco é caracterizado pelo fato de que mais de $4 \%$ dos imóveis visitados nestes municípios tiveram larvas do mosquito encontradas. No município estudado foram encontradas larvas do Aedes aegypt em 0,5\% dos imóveis, índice considerado satisfatório, porém a quantidade de casos notificados da doença cresceu 64\% entre os meses de outubro de 2015 e janeiro de 2016.

Alguns fatores podem ser relacionados ao alto nível de infestação do mosquito e, consequentemente, ao aumento da incidência das doenças transmitidas por ele, tal como a falta de informação e envolvimento da população, o excesso de lixo que acumula água na cidade e a falta de fiscalização mais criteriosa.

Os objetivos deste artigo são demonstrar a possibilidade de utilização de um aplicativo criado, como uma ferramenta de análise da eficiência das diretrizes estabelecidas pelo Ministério da Saúde e pela Secretaria Estadual de Saúde, assim como apresentar insumos para se repensar o formato de trabalho que é implementado atualmente nos municípios.

Pretende-se também investigar os possíveis benefícios que podem ser gerados através do acompanhamento e mensuração contínua e detalhada dos trabalhos desempenhados em campo pelos ACE, buscando:

a) Conhecer o histórico e classificar cada imóvel, cada região e cada cidadão em relação aos focos e criadouros existentes.

b) Medir a real efetividade de cada ação de combate às endemias.

c) Fornecer uma ferramenta útil para direcionar recursos.

d) Envolver a população no processo de controle do Aedes aegypti.

Como parte do embasamento necessário para a elaboração deste artigo foi feita uma pesquisa exploratória e coleta de dados estruturados em um município da região metropolitana de Belo Horizonte, em Minas Gerais, que utilizou, em caráter experimental, o aplicativo móvel criado para informatização do trabalho de campo da sua equipe de endemias. Segundo Cassarro (2011), a coleta de dados em formato digital e mensuração de indicadores de qualidade, é ferramenta fundamental para se implementar um modelo de gestão baseado em informações, e também para tomar ações rápidas e corrigir problemas enquanto ainda são incipientes. 


\section{0 combate a endemias e o aplicativo criado}

O combate às endemias é de fundamental importância para a saúde de uma população. Todo investimento feito nestes processos podem ser considerados investimentos em prevenção, promoção e educação em saúde, o que, tendo em vista a Lei $n^{\circ}$ 8080/90, que regula as ações e serviços da saúde, está intimamente ligado com um dos objetivos principais do Serviço Único de Saúde (SUS). O artigo $5^{\circ}$ do Capítulo I desta lei define como um dos objetivos do Sistema Único de Saúde: a assistência às pessoas por intermédio de ações de promoção, proteção e recuperação da saúde, com a realização integrada das ações assistenciais e das atividades preventivas.

Uma das questões fundamentais para que o controle do mosquito Aedes aegypti seja eficiente e diminua a incidência das doenças transmitidas por ele, está relacionada com o bom trabalho feito pelos ACE. E, como estes agentes trabalham de forma independente, sem acompanhamento ou supervisão constante, sua atuação nem sempre é satisfatória. Estes profissionais possuem um papel fundamental no enfrentamento do problema de saúde pública relacionado ao controle e prevenção de focos do mosquito Aedes aegypti.

Segundo Ceccim (2005), a informação da população pode ser uma arma poderosa, quando se trata da eliminação de um vetor que está presente em $80 \%$ dos casos, dentro da casa das pessoas.

É importante observar que o grande potencial de multiplicação do mosquito exige que o auto cuidado, para ser eficiente, seja feito por todo cidadão. Apenas um imóvel que estiver descuidado quanto aos criadouros e focos, pode gerar mosquitos suficientes para trafegar por todo um bairro.

Desta forma, o processo de conscientização e educação da população, para a eliminação deste mal, deve vir acompanhado de um processo consistente de investigação e acompanhamento dos imóveis. Vale ressaltar que nem todos os imóveis de um município são residenciais. Os imóveis públicos, vias públicas e imóveis não habitados devem ter atenção especial da vigilância epidemiológica municipal.

Os dados coletados durante o trabalho das equipes de saúde, no município em questão, assim como na maioria dos municípios do Brasil, eram restritos a um pedaço de papel, no qual se registrava a contagem dos imóveis visitados. No máximo era registrado por endereço 
ou por tipo de imóvel. Estes dados eram utilizados para prestação de contas nos sistemas do DataSus $^{3}$ e após este registro eram armazenados.

Este processo de trabalho impossibilitava que o município tratasse de forma especial e mais cuidadosa os imóveis mais problemáticos, ou que conhecesse o perfil de focos ou criadouros de cada região. Isso, caso fosse apurado, poderia ser uma informação importante no processo de comunicação com a população e monitoramento dos focos. Segundo Cassarro (2011), o conhecimento profundo dos dados é o primeiro passo para se entender as dimensões de um problema e tomar decisões baseadas em informações.

Ainda, devido à falta de coleta e armazenamento adequado dos dados, é extremamente difícil, por parte dos municípios, medirem a qualidade dos trabalhos feitos pelos ACE. Esta realidade impede os municípios de ajustarem a conduta de agentes que não executam o trabalho conforme as diretrizes e metodologias preconizadas e, até mesmo, de bonificar os agentes que conseguem se destacar em qualidade e conscientização dentro de sua área de trabalho. Segundo França (2004), a mensuração e valorização do trabalho de um profissional é um importante ponto para que este profissional tenha satisfação no seu trabalho e se sinta valorizado e instigado a trabalhar da melhor forma possível.

Ao propor soluções para o cenário em questão, se levou em consideração a realidade dos municípios e da saúde pública municipal, que geralmente detém as características de falta de verbas, regulamentação dos processos com adequação à legislação vigente e a necessidade de interação com sistemas existentes.

Com estes pré-requisitos e o cenário do processo em foco, foi proposta uma solução na forma de um aplicativo criado para dispositivos móveis, que ocorreu em três etapas, utilizando a tecnologia como fator viabilizador.

\subsection{Primeira etapa, o Agente de Combate às Endemias - ACE}

O objetivo foi informatizar todo o processo executado pelos agentes de campo, os ACE. A proposta foi de que eles trabalhassem utilizando dispositivos móveis (como tablets ou smartphones), equipados com o aplicativo criado, específico para coleta de dados das visitas realizadas. Foi levada em consideração a importância de que a coleta fosse semelhante ao trabalho realizado atualmente no papel, conservando termos, formatos e ordenação dos

\footnotetext{
${ }^{3}$ DataSus é o nome do departamento de informática do Sistema Único de Saúde do Brasil. Trata-se de um órgão da Secretaria de Gestão Estratégica e Participativa do Ministério da Saúde com a responsabilidade de coletar, processar e disseminar informações sobre saúde.
} 
dados. Dessa forma, a transição da coleta em papel para a digital ocorreu de forma mais natural.

Com essa modificação no processo de coleta, já foi possível iniciar a medição de uma série de indicadores de qualidade, como tempo médio de cada visita, tempo médio de deslocamento, localização exata de cada visita (usando o GPS do dispositivo), qualidade dos dados coletados e cumprimento adequado do processo de trabalho estabelecido.

Como cada município poderia ter a necessidade de coletar dados específicos, dependendo de suas necessidades, levou-se em consideração a importância de que a ferramenta fosse flexível o suficiente para permitir essas adequações de comportamento.

Com o agente equipado com este tipo de tecnologia, pôde-se ainda fortalecer o processo de educação em saúde, que faz parte da missão dos ACE. Neste caso, o agente teve a possibilidade de exibir um vídeo educativo no dispositivo, ao invés de usar sua habilidade pessoal para informar ao cidadão sobre os cuidados necessários no controle da infestação, por exemplo. Sendo assim, a comunicação sobre aspectos de educação em saúde pôde ser feita de forma homogênea e mais interativa, cenário que ajudou no desafio de envolver a população no combate aos focos e criadouros.

Para se cumprir o requisito de realização deste trabalho com baixo custo, os dispositivos deveriam ser os de custo mais reduzido e trabalhar sem acesso à internet, durante as visitas. Sendo assim, os dados coletados durante um dia de trabalho eram enviados para uma central quando o agente voltava para seu ponto de apoio, cujo local demandou internet disponível para envio dos dados para um servidor próprio de Cloud Computing (armazenamento de dados em nuvem).

Outros fatores que colaboraram com o requisito financeiro (baixo custo) foram gerados pela informatização das visitas, que possibilitou eliminar a necessidade de digitação dos dados e consolidação manual dos dados, eliminar problemas de transcrição de dados e implementar a supervisão automatizada de alguns critérios de visita. Todos estes fatores melhoraram a produtividade dos agentes e diminuíram a necessidade de intervenção humana no processo. 


\section{1 Segunda etapa, a Gestão Municipal de Saúde}

Com todos os dados coletados em formato digital, sem a necessidade de transcrição e presentes em fonte de dados única e centralizada, foi aberta uma possibilidade importante para a gestão. Pôde ser criada uma sala de situação e análise.

Ter a visão completa da situação endêmica no município é pré-requisito para a gestão de saúde tornar ações assertivas, e direcionar investimentos para os processos que terão melhores resultados. Dessa forma, a existência de uma ferramenta de análise dos dados gerados é imprescindível para o gestor.

Podemos dividir este tipo de ferramental tecnológico utilizado, em três subtipos, igualmente importantes: análise de dados, georreferenciamento e ferramenta de comunicação direta. Atualmente, existem soluções de baixo custo e até mesmo gratuitas para realização dessas análises. Bastaria ao município ter profissional capacitado ou contratar um serviço especializado para implantação.

Com as ferramentas de análise de dados, o gestor pode conseguir traçar perfis de focos e casos registrados no município. Poderá, também, classificar as regiões e os imóveis de acordo com o nível de risco que cada um representa e definir indicadores e metas a serem alcançadas pelas equipes.

A Figura 1, a seguir, demonstra esta possibilidade, a partir de dados fictícios lançados no aplicativo criado. 
Figura 1: Painel de situação com dados fictícios para exemplificar a ferramenta de análise de dados

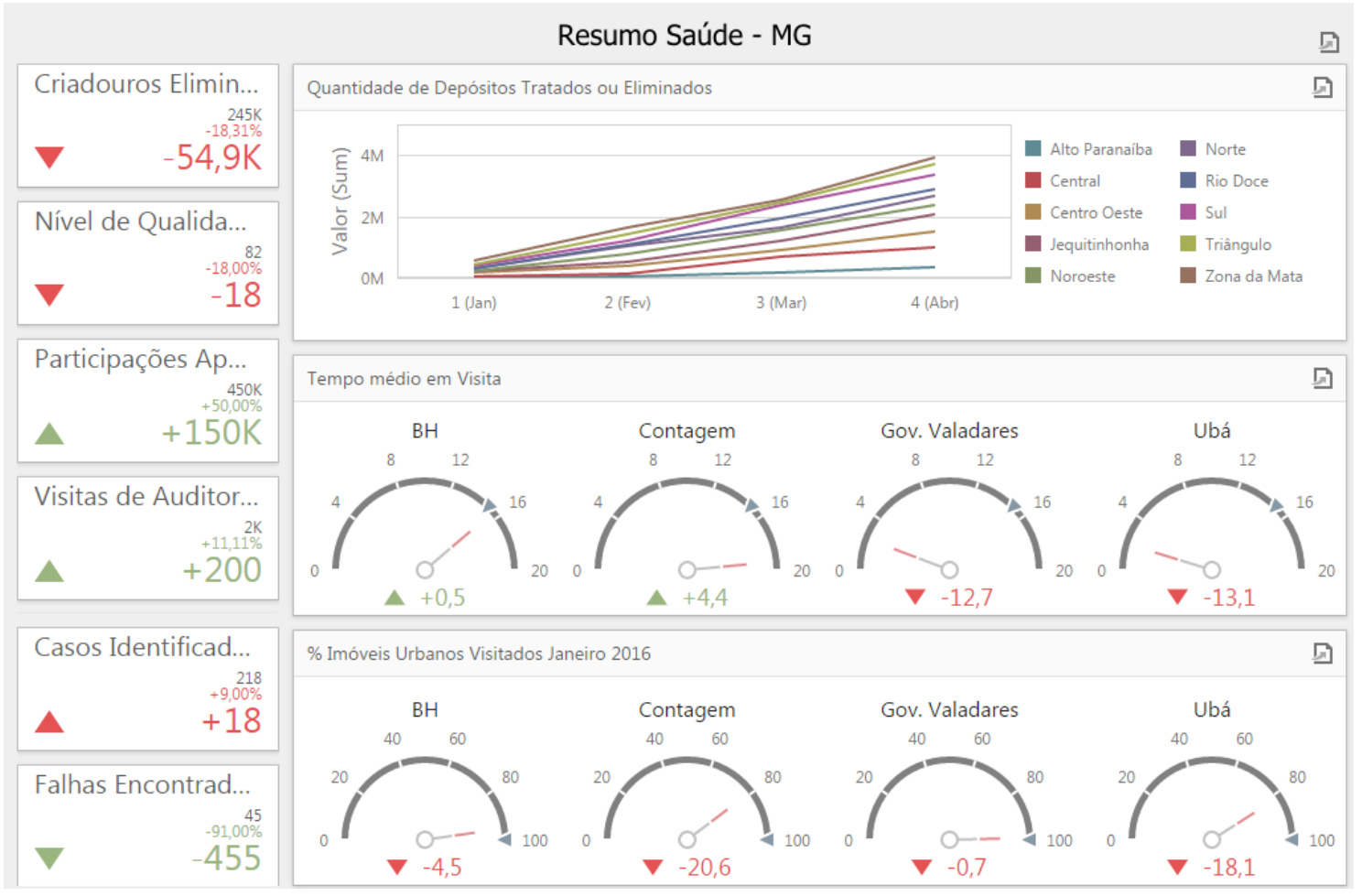

Fonte: Elaborado pelos autores

Uma outra possibilidade é a visualização dos imóveis e visitas feitas no mapa do município, que permite ao gestor entender de forma clara a situação de cada região. $\mathrm{O}$ georreferenciamento possibilita ao gestor cuidar de forma especializada cada ponto em seu município. Esta ferramenta revela sua importância quando entendemos que os bairros e regiões, muitas vezes, possuem peculiaridades e comportamentos específicos, dependendo de suas características sociais, econômicas e culturais. Ainda trabalhando com dados fictícios, agora projetados no município de Vespasiano em Minas Gerais, a Figura 2 apresenta um exemplo desta possibilidade de visualização proporcionado pelo aplicativo em questão. 


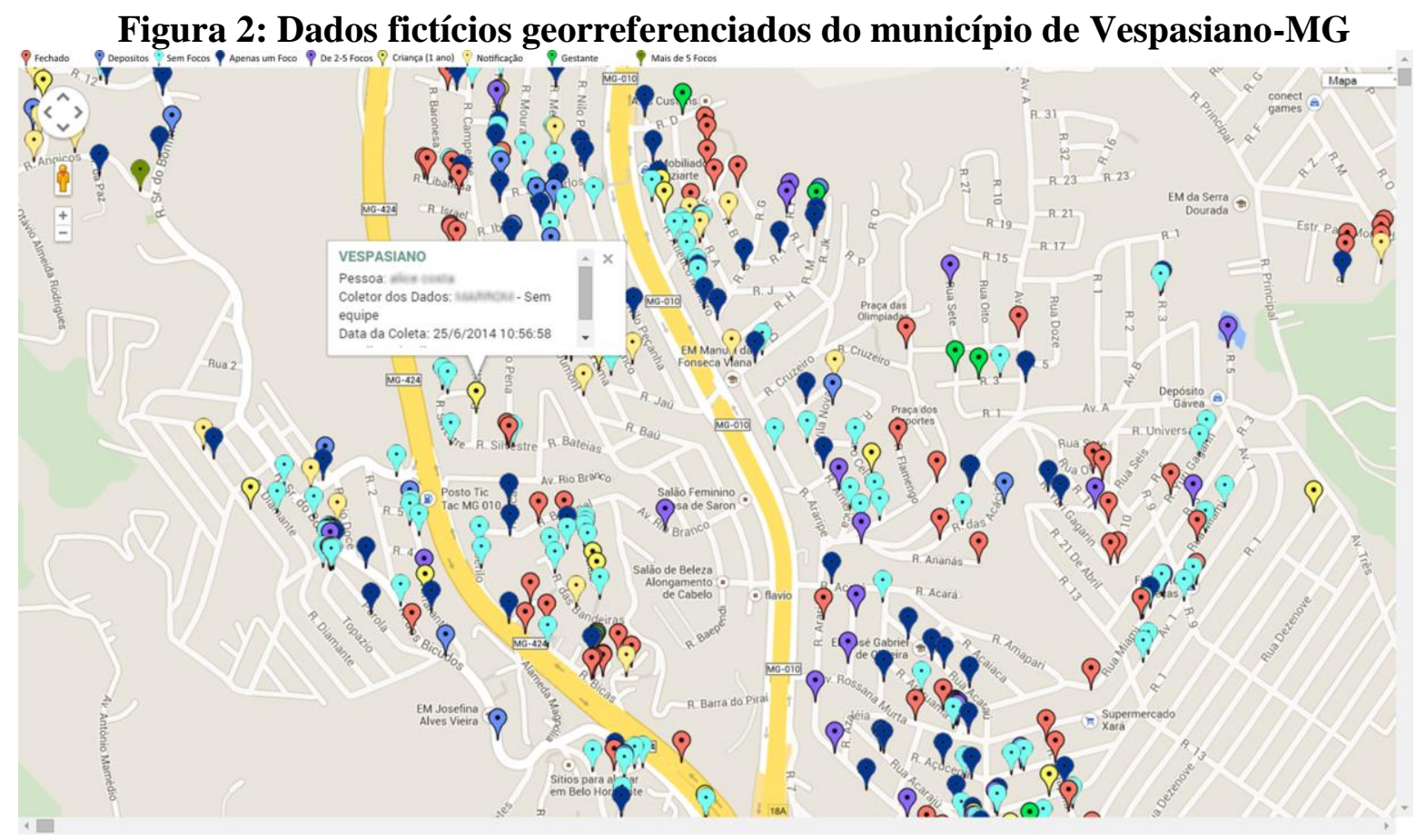

Fonte: Elaborado pelos autores

Conhecendo cada imóvel e seu histórico de cuidado com criadouros e focos, se torna um ponto importante que a gestão tenha formas de se comunicar constantemente com os responsáveis de cada imóvel, principalmente com os que possuem histórico recorrente de criadouros e focos encontrados. Desta forma, o município aumenta sua presença e a conscientização das pessoas com maior necessidade de envolvimento no combate ao mosquito e não restringe essa presença somente às visitas realizadas em períodos pontuais. Existem atualmente algumas formas de se comunicar com as pessoas utilizando tecnologias com baixo custo e de fácil implantação, como é o caso do envio de mensagem de celular, o envio de correio eletrônico ou até mesmo a interação com comunicadores instantâneos amplamente difundidos, como o WhatsApp.

\section{3 Terceira etapa, o cidadão.}

Um dos pontos cruciais para a drástica diminuição de incidência das doenças transmitidas pelo mosquito Aedes aegypti é o envolvimento da população. Segundo Glasser; Gomes (2000), cerca de $80 \%$ dos focos deste mosquito se encontram dentro dos imóveis.

As duas primeiras etapas propostas, já atuam neste sentido. A primeira levantando dados e levando informações e uma forma de educação mais dinâmica para os cidadãos. A 
segunda, viabilizando uma comunicação constante e assertiva com a população. Porém nestas etapas o cidadão atua apenas passivamente no processo. Sendo assim, para reforçar e envolver ainda mais as pessoas que estão mais próximas aos focos, foi implementado um canal de participação ativa. Este canal abriu a possibilidade ao cidadão mais envolvido na causa para denunciar possíveis criadouros e focos do mosquito, avaliar a visita que recebeu de um ACE e, até mesmo, registrar um caso suspeito ou confirmado de uma das doenças transmitidas pelo mosquito Aedes aegypti.

Um formato interessante e que vem ganhando mais adeptos a cada dia é a utilização de aplicativo móvel para este fim específico. Neste caso, cada cidadão poderia ter este aplicativo em seu celular e utilizá-lo para participar e interagir com o município.

Essas três etapas, se adequadamente implementadas, podem trazer uma série de benefícios para a gestão municipal de saúde, como a melhoria de produtividade, redução de custos, possibilidade de valorização dos ACE, reforço da cultura do combate aos focos de infestação de mosquitos e uma população mais informada e comprometida com esta causa. Todos estes benefícios apontam para um resultado almejado pelos municípios brasileiros, ou seja, a redução significativa da incidência de casos de Dengue, Zika e Chincungunya.

\section{Conclusão}

A tecnologia, quando aplicada com conhecimento, pode ser uma poderosa arma para o combate ao mosquito Aedes aegypti. É possível implantarmos as tecnologias mais modernas em prol desta causa, com investimentos que são factíveis, mesmo em municípios com recursos parcos.

Com a qualificação automática das visitas e o acompanhamento constante do trabalho executado pelos ACE, um município aumentaria significativamente sua capacidade de ação, sem a necessidade de aumentar o quantitativo de funcionários. O aplicativo criado pode ainda ajudar a envolver o cidadão no combate aos focos e criadouros do mosquito, através dos processos de educação e participação ativa.

Pode-se concluir que a utilização da tecnologia traria benefícios reais para o processo de combate às endemias nos municípios brasileiros. A adoção dos processos de informatização e gestão baseada em informações, amplamente utilizado em outras áreas e setores privados, resultaria em uma queda dos índices de infestação e de incidências das doenças transmitidas pelo mosquito Aedes aegypti. 
Como possível evolução deste trabalho, pode-se considerar a aplicação das tecnologias e metodologias de qualificação citadas aqui, para outros setores da saúde pública, como o trabalho executado pelo fiscal de vigilância sanitária e até mesmo os outros processos presentes no trabalho do ACE. 


\section{REFERÊNCIAS}

BRASIL. Lei $\mathrm{n}^{\circ}$ 8080, de 19 de setembro de 1990. Dispõe sobre as condições para a promoção, proteção e recuperação da saúde, a organização e o funcionamento dos serviços correspondentes e dá outras providências. Diário Oficial da União, Brasília, 19 set. 1990.

CASSARRO, Antônio Carlos. Sistemas de Informações para Tomadas de Decisões. São Paulo, Tomson, 2011.

CECCIM, Ricardo Burg. Educação Permanente em Saúde: descentralização e disseminação de capacidade pedagógica na saúde. Ciência e Saúde Coletiva, Rio de Janeiro, v. 10, n. 4, p. 975-986, 2005.

FRANÇA, Ana Cristina Limongi. Qualidade de Vida no Trabalho - QVT: conceitos e práticas nas empresas da sociedade pós indústria. São Paulo, Atlas, 2004.

GLASSER, Carmen Moreno, GOMES, Almério de Castro. Infestação do Estado de São Paulo por Aedes Aegypti e Aedes Albopictus, Revista Saúde Pública, São Paulo, v.34. n.6, Dez. 2000.

PORTAL DA SAÚDE, Disponível em: <http://portalsaude.saude.gov.br/>. Acesso em: 3 de Mar. 2016. 